\title{
Condenações post mortem em perus (Meleagris gallopavo) criados na região oeste catarinense e abatidos sob Inspeção Federal ${ }^{\star}$
}

\section{Postmortem condemnations in turkeys (Meleagris gallopavo) slaughtered under federal supervision in the west of Santa Catarina State*}

\author{
Rodrigo Braga Macahyba, ${ }^{* *}$ Sérgio Borges Mano, ${ }^{* * *}$ Mônica Queiroz de Freitas, ${ }^{* * *}$ Rami Fanticelli Baptista****
}

\begin{abstract}
Resumo
Considerando o fato de que, no Brasil, ainda são escassas as informações sobre as causas de condenações de perus (Meleagris gallopavo) em matadouros, os objetivos do presente trabalho foram o estudo das condenações post mortem em perus abatidos, sob Inspeção Federal, na região oeste do estado de Santa Catarina, a verificação da influência da variação de temperatura média ambiente sobre os percentuais de condenações, bem como a verificação dos índices de condenações dos municípios participantes do sistema de integração estudado. Os índices de condenações contabilizados foram obtidos pelo levantamento dos dados oficiais da Inspeção post mortem do Serviço de Inspeção Federal ㄲo 104 e as informações climáticas foram conseguidas junto à Empresa de Pesquisa Agropecuária e Extensão Rural de Santa Catarina (EPAGRI). Os resultados demonstraram que, das 11.763 .539 aves contabilizadas, $530.418(4,5 \%)$ tiveram algum tipo de condenação post mortem. A maioria das condenações parciais (399.621-3,4\%). As carcaças condenadas totalmente somaram 130.797 $(1,1 \%)$. De acordo com os resultados obtidos, concluímos que: o conjunto das condenações parciais post mortem em perus é maior do que o conjunto das condenações totais, sendo a aerossaculite a principal causa de condenação; existe uma tendência positiva entre o aumento da temperatura média ambiente na região oeste catarinense e o aumento dos índices de condenações post mortem em perus; ocorre uma uniformidade na criação de perus na região oeste catarinense, dada a semelhança entre os índices de condenações encontrados nos diversos municípios participantes do sistema de integração estudado.
\end{abstract}

Palavras-chave: perus, inspeção, condenações post mortem.

\begin{abstract}
Considering the fact that, in Brazil, there is little information about the causes of turkeys' (Meleagris gallopavo) condemnations in slaughterhouses, the objectives of the current paper were to study the postmortem condemnations in turkeys slaughtered under Federal Supervision in the West of Santa Catarina State, to verify the influence of the weather temperature range in the percentage of condemnations, as well as, to verify the rates of condemnation in the participating areas of the system studied. The condemnation rates were acquired through the official survey, carried out by the postmortem Federal Inspection Service nr. 104 and weather reports were acquired through the Farming, Cattle Raising and Rural Extension of Santa Catarina Company (EPAGRI). The results show that, among de 11,763,539 million birds accountancy, 530,418 thousand (4.5\%) had some kind of postmortem condemnation. Most condemnations were partial (399,621 thousand - 3.4\%). The birds totally condemned added up to 130,797 thousand $(1.1 \%)$. According to the results found, we came to the conclusion that: the amount of partial postmortem condemnation in turkeys is bigger than the amount of total postmortem condemnation, being the airsacculitis the leading cause of condemnation; there is a conclusive relation between the increase of environmental temperature in the West of Santa Catarina and the increase of postmortem turkey condemnation numbers; there is a pattern in turkey raising in the West of Santa Catarina, given the similarity among the condemnation rates found in different cities where this study took place.
\end{abstract}

Keywords: turkeys, inspection, postmortem condemnation.

\footnotetext{
* Parte da dissertação de mestrado do primeiro autor em Higiene Veterinária e Processamento Tecnológico de Alimentos de Origem Animal, Universidade Federal Fluminense (UFF), Niterói, RJ.

** Médico-veterinário, mestre em Veterinária, bolsista CAPES - Rua Domingos Ferreira, n. $\stackrel{0}{108}$ apto 401 Copacabana - Rio de Janeiro, RJ - CEP: 22050-010 - rodrigomacahyba@bol.com.br

*** Médico-veterinário, Doutor em Veterinária, professor do Departamento de Tecnologia de Alimentos da Faculdade de Veterinária da UFF - mtasbm@vm.uff.br **** Médica-veterinária, doutora em Veterinária, professora do Departamento de Tecnologia de Alimentos da Faculdade de Veterinária da UFF - mqueiroz@vm.uff.br

***** Médica-veterinária, mestre em Veterinária, bolsista CAPES - rfanticelli@ig.com.br
} 


\section{Introdução}

A crescente globalização dos mercados praticamente eliminou as fronteiras naturais e, em razão disso, as barreiras sanitárias ganharam relevância, podendo representar o diferencial de competitividade no comércio agrícola internacional. No Brasil, o crescimento constante da produção e do consumo de carnes de aves, as crescentes exportações de produtos de origem animal e o risco de incidência das enfermidades transmitidas por alimentos exacerbam a importância do Serviço de Inspeção Federal como orientador e fiscalizador da integridade desse processo como um todo. Neste contexto, a Inspeção Federal visa garantir aos consumidores um alimento de alto valor nutricional e, principalmente, seguro, além de consolidar a geração de divisas para o país.

A região oeste catarinense há muito tempo vem despontando no cenário agro-industrial brasileiro como uma das principais regiões produtoras de aves e suínos. Nessa região destaca-se com bastante notoriedade o município de Chapecó, responsável, entre outros, pela maior parte do abate e do processamento de perus do país.

A produção e o consumo de carne de peru gera benefícios para as indústrias (maior rendimento de carcaça em relação ao frango e maior valor agregado do produto final), para os criadores (maior valor pago pelas indústrias por ave abatida e aves mais resistentes a enfermidades) e para os consumidores (carne com menor teor de gordura). Entretanto, apesar do aumento dos índices de produção e consumo, estes ainda estão muito abaixo dos índices de outros tipos de carnes produzidos e consumidos no Brasil, bem como dos índices de países em que o hábito de consumo de carne de peru é maior como, por exemplo, nos Estados Unidos ou em países da Comunidade Européia.

Tendo em vista a escassez de informações sobre as causas de condenações em perus no Brasil, os objetivos do presente trabalho foram o estudo das condenações post mortem em perus abatidos, sob Inspeção Federal, na região oeste catarinense, a verificação da influência da variação de temperatura média ambiente sobre os percentuais de condenações, bem como a verificação dos índices de condenações dos municípios participantes do sistema de integração estudado.

\section{Material e métodos}

Nos 24 meses utilizados no levantamento e colheita de dados (agosto de 1999 a julho de 2001), foram contabilizadas um total de 11.763 .539 aves. Esse número não corresponde ao total de perus abatidos pela indústria nesse período, e sim ao total de aves com características que se encaixavam aos objetivos do trabalho, isto é, procedeu-se uma seleção preliminar dos dados que iriam ser utilizados. Essa seleção era feita pela análise dos seguintes documentos oficiais do Serviço de Inspeção Federal n. ํ 104: "Programação Diária de Abate" e "Movimento Diário de Abate e Condenações". O primeiro era sempre fornecido pelo Matadouro-Frigorífico com 24 horas de antecedência ao abate, e o segundo era elaborado pela própria Inspeção Federal, a partir dos dados de condenações diárias anotados no "Mapa Nosológico de Doenças e Condenações".

\section{Faixa de peso dos lotes}

Na Programação Diária de Abate eram analisadas as faixas de peso de cada um dos lotes que foram abatidos, sendo utilizados os dados de condenações apenas dos lotes com peso variando entre 10 e 20 quilos, o que correspondia a um tempo de criação entre 100 e 180 dias. A escolha dessa faixa de peso deve-se ao fato de que esta era a de maior volume de abate da indústria, cuja produção de carne de peru é voltada, principalmente, para o setor de cortes. Outro fator que levou a escolha dessa faixa de peso é que seu abate ocorreu durante o ano inteiro, possibilitando, desta forma, a comparação dos dados de condenação com a variação climática em todos os meses do ano. Além disso, os perus nessa faixa de peso ficaram mais dias nos aviários em fase de engorda, aumentando as chances de incidência de doenças e, conseqüentemente, de um maior índice de condenações post mortem.

\section{Identificação dos municípios e integrados}

A identificação e a numeração dos municípios da região oeste catarinense que tiveram avicultores participantes do sistema de integração pesquisado, no período entre agosto de 1999 e julho de 2001, foram feitas a partir da "Lista de Avicultores Integrados" fornecida pela empresa.

Durante o período de 24 meses estipulado para o levantamento de dados, a empresa na qual foi desenvolvido o trabalho contou com cerca de 1.739 avicultores integrados divididos em 19 municípios da região oeste catarinense. Cada um dos lotes abatidos e selecionados para terem seus dados contabilizados tinha seu município identificado de acordo com seu respectivo avicultor, sendo que a numeração dada a cada um dos municípios (1 a 19) seguiu o critério de ordem alfabética.

\section{Organização dos dados de condenação e dados climáticos}

Os dados colhidos foram inicialmente digitados em planilhas específicas e individuais para cada um dos 24 meses. A partir das 24 planilhas iniciais foram elaborados uma planilha geral e os gráficos com o total de condenações durante os 24 meses contabilizados.

As informações climáticas utilizadas foram as temperaturas médias ambiente mensais da região oeste catarinense referentes ao mesmo período de levantamento de dados. Utilizando-se os dados climáticos e os dados de condenações, plotaram-se gráficos de dois eixos com três escalas (Figuras 1 e 2), verificando-se, desta forma, se houve variação dos índices de cada uma das principais causas de condenações post mortem encontradas no decorrer dos 24 meses em virtude da variação mensal da temperatura média ambiente.

\section{Inspeção post mortem}

A Inspeção post mortem foi efetuada conforme o preconizado pela Portaria n. ${ }^{\circ} 210$ (Brasil, 1998), ou seja, a partir do exame visual macroscópico das carcaças e suas respectivas vísceras nas chamadas "Linhas de Inspeção", a saber: Linha "A" (exame interno da cavidade celomática: pulmões, sacos aéreos, rins e órgãos sexuais), Linha "B" (exame de vísceras: coração, fígado, moela, baço, intestinos, ovários e ovidutos nas poedeiras) e Linha "C" (exame externo: pele, articulações, membros e outras estruturas). Cada carcaça era examinada individualmente e, conforme o caso, eram feitas palpações e cortes. Quando houve a necessidade de um exame mais acurado, as carcaças e suas respectivas vísceras foram desvi- 
adas para o Departamento de Inspeção Final (DIF) para que o veterinário de plantão determinasse o destino adequado. As diversas causas de condenação que ocorreram nas Linhas de Inspeção ou no DIF foram marcadas no Ábaco.

\section{Contabilização das condenações post mortem}

Ao final de cada lote foi dado um intervalo de cerca de 20 ganchos entre lotes, garantindo, dessa forma, a correlação ante e post mortem dos lotes. Nesse intervalo, cada agente de inspeção das linhas correspondentes tinha a função de repassar o número de condenações do Ábaco para o Mapa Nosológico de Doenças e Condenações e, em seguida, zerar novamente o Ábaco, evitando, desta forma, a confluência com os dados de condenações do lote seguinte. Conforme descrito anteriormente, esse mapa foi utilizado na elaboração do Movimento Diário de Abate e Condenações.

\section{Análise estatística}

A análise estatística constou de uma análise descritiva simples, realizando-se um estudo comparativo entre a média e a proporção dos diversos dados estudados, com utilização de tabelas e gráficos para uma melhor visualização. Para a realização da referida análise estatística descritiva e confecção dos gráficos utilizou-se o programa Microsoft Excelß.

\section{Resultados e discussão}

\section{Aves abatidas $x$ Condenações post mortem}

Os resultados obtidos dos percentuais de condenações parciais e totais post mortem encontradas entre agosto de 1999 e julho de 2001 demonstram que as condenações parciais representaram a maioria das causas de condenações encontradas, conforme visualizado na Tabela 1.

Tabela 1 - Quantidade de condenações post mortem parciais e totais e seus respectivos percentuais sobre 11.763 .539 aves estudadas, no período entre agosto de 1999 e julho de 2001.

\begin{tabular}{lccc}
\hline & \multicolumn{2}{c}{$\begin{array}{c}\text { Critério de condenação } \\
\text { post mortem }\end{array}$} & \multirow{2}{*}{ SOMA } \\
\cline { 2 - 3 } & Parcial & Total & \\
\hline Carcaças condenadas & 399.621 & 130.797 & 530.418 \\
Percentual (\%) & 3,40 & 1,11 & 4,51 \\
\hline
\end{tabular}

O maior índice de condenações parciais confirmou o esperado antes da realização do trabalho em virtude desse critério de condenação ser, normalmente, mais freqüente na rotina de Inspeção post mortem de aves. Entretanto, essa maioria ocorreu em decorrência do grande índice de condenações parciais por aerossaculite que, desta forma, veio a constituir a principal causa de condenação encontrada.

De acordo com a Tabela 2, observamos as proporções, desta vez sobre o total de aves condenadas, das quantidades e percentuais de condenações parciais por aerossaculite comparados ao conjunto das demais causas de condenações parciais e ao conjunto das condenações totais.
Tabela 2 - Quantidades e percentuais de condenações post mortem por aerossaculite parcial, outras condenações parciais e condenações totais sobre o total de aves condenadas, no período entre agosto de 1999 e julho de 2001.

\begin{tabular}{lcr}
\hline Causas de condenações post mortem & Quantidade & $\%$ \\
\hline Aerossaculite parcial & 356.614 & 67,0 \\
Outras condenações parciais & 43.007 & 8,0 \\
Condenações totais & 130.797 & 25,0 \\
\hline SOMA & 530.418 & 100,0 \\
\hline
\end{tabular}

A observação durante a elaboração do trabalho de lotes de perus com incidência de aerossaculite superior a $80 \%$ está de acordo com a dinâmica populacional dos animais de produção descrita por Neto (2001), quando este afirma que uma única ave doente é capaz de disseminar a enfermidade a todo o plantel.

O elevado índice de condenações post mortem por aerossaculite encontrado também está de acordo com as afirmações de Herenda e Franco (1996) e Castro (2000), quando estes autores relatam que a região dos sacos aéreos em aves é altamente susceptível a doenças.

Embora não fosse objeto deste estudo, concordamos com Castro (2000) no que diz respeito à inviabilidade do diagnóstico da aerossaculite apenas pela observação macroscópica das lesões, mesmo havendo características possíveis de serem identificadas baseadas no agente etiológico (Di Fábio, 1992; Herenda e Franco, 1996).

Ainda com relação à aerossaculite, constatamos que o percentual encontrado em nosso trabalho (3,03\%) diferiu significativamente de Herenda e Franco (1996), que relataram índices apresentados pelo "United States Department of Agriculture" (USDA) entre 1990-1992 e pelo "Agriculture and Agri-Food Canada" (AAFC) entre 1990-1994. Estes índices alcançaram, respectivamente, percentuais máximos de $0,42 \%$ e $0,39 \%$.

As quantidades e percentuais das principais causas de condenações postmortem parcial e total podem ser observadas separadamente nas Tabelas 3 e 4 .

Tabela 3 - Quantidades e percentuais das principais causas de condenação parcial sobre o total de aves estudadas, no período entre agosto de 1999 e julho de 2001

\begin{tabular}{lrr}
\hline Causas de Condenação Parcial & Quantidade & \multicolumn{1}{c}{$\%$} \\
\hline Aerossaculite parcial & 356.614 & 3,03 \\
Artrite parcial & 789 & 0,01 \\
Contaminação parcial & 14.516 & 0,12 \\
Contusão/Fratura parcial & 458 & 0,004 \\
Dermatose parcial & 18.289 & 0,16 \\
Escaldagem excessiva parcial & 3.693 & 0,03 \\
Sangria inadequada parcial & 411 & 0,003 \\
Outras & 4.851 & 0,04 \\
\hline Soma & 399.621 & 3,4 \\
\hline Total de aves estudadas & 11.763 .539 & \\
\hline
\end{tabular}


Tabela 4 - Quantidades e percentuais das principais causas de condenação total sobre o total de aves estudadas, no período entre agosto de 1999 e julho de 2001

\begin{tabular}{lrc}
\hline \multicolumn{1}{c}{ Causas de Condenação Total } & Quantidade & $\%$ \\
\hline Aspecto repugnante & 33.713 & 0,29 \\
Artrite & 17.400 & 0,15 \\
Caquexia & 2.320 & 0,02 \\
Colibacilose & 15.908 & 0,13 \\
Contaminação & 3.279 & 0,03 \\
Contusão/Fratura & 1.172 & 0,01 \\
Dermatose & 42.487 & 0,36 \\
Escaldagem excessiva & 8.983 & 0,08 \\
Evisceração retardada & 1.697 & 0,01 \\
Sangria Inadequada & 1.200 & 0,01 \\
Outras & 2.638 & 0,02 \\
\hline Soma & 130.797 & 1,11 \\
\hline Total de aves estudadas & 11.763 .539 & \\
\hline
\end{tabular}

\section{Temperatura $x$ condenações}

A influência da variação anual de temperatura média ambiente na região oeste catarinense sobre os índices das causas de condenações post mortem ficou mais bem caracterizada na principal condenação encontrada, a aerossaculite parcial.

Na Figura 1 pode-se verificar essa influência ao ser observado que o aumento e a posterior diminuição gradativa da temperatura média ambiente no decorrer dos meses eram, em seguida, acompanhados pelo aumento e diminuição dos índices dessa condenação.

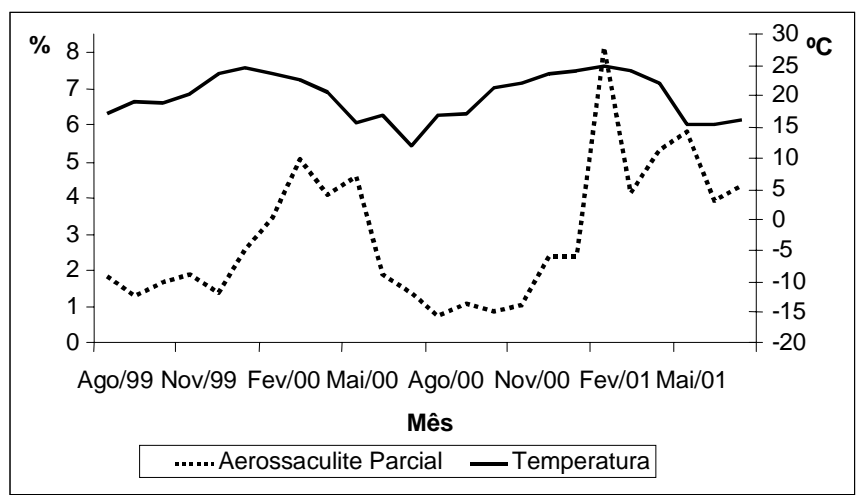

Figura 1 - Comparação da variação dos percentuais de condenações por aerossaculite parcial com a variação da temperatura média ambiente na região oeste catarinense no período entre agosto de 1999 e julho de 2001

Nas demais condenações parciais não se observou uma correspondência evidente da variação da temperatura média ambiente com suas respectivas incidências. Pôde-se apenas verificar que, ao contrário da aerossaculite parcial, a dermatose parcial teve uma maior tendência de aumento em seus índices de condenações em temperaturas mais baixas.

As principais condenações de caráter total encontradas (aspecto repugnante, artrite, colibacilose e dermatose), também tiveram, em menor escala, o aumento de seus percentuais de condenação após o aumento de temperatura média ambiente, conforme visualizado na Figura 2

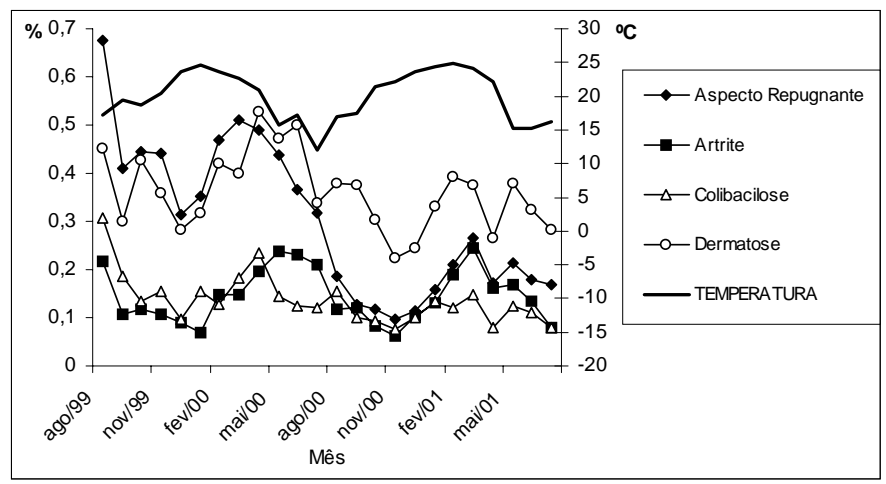

Figura 2 - Comparação da variação dos percentuais das principais condenações totais encontradas com a variação da temperatura média ambiente na região oeste catarinense no período entre agosto de 1999 e julho de 2001

Portanto, nossos resultados estão de acordo com os resultados de Fabricio (1994), quando o referido autor obteve um maior índice de perdas no verão, ou seja, em temperaturas mais altas.

A verificação do aumento dos índices de condenações concomitantemente ao aumento da temperatura média ambiente também está de acordo com o descrito por Fioretto (1993), quando este menciona que a temperatura começa a ser prejudicial às aves a partir dos $24^{\circ} \mathrm{C}$.

Ferreira e Knöbl (2000) e Jordan et al. (1990) concordam que o aparecimento de enfermidades relacionadas com Escherichia coli está diretamente ligada ao ambiente, incluindo, entre outros fatores predisponentes, extremos de temperatura. Fazendo uma correlação desta afirmação com o que Herenda e Franco (1996) descreveram, isto é, que nas doenças respiratórias das aves há a presença constante desse microrganismo, pode-se especular que o aumento dos índices de aerossaculite em temperaturas mais altas encontrados no presente trabalho, possa estar tendo, como um dos principais agentes, a $E$. coli.

Com exceção dos índices de dermatose parcial, não houve concordância entre os dados encontrados em nosso trabaIho com os dados da Agriculture and Agri-Food Canada (AAFC), apresentados por Herenda e Franco (1996), onde os maiores índices de condenações foram encontrados no inverno e na primavera, ou seja, nas estações mais frias.

\section{Índices de condenações $x$ municípios}

Entre os 19 municípios participantes do sistema de integração estudado verificou-se um equilíbrio dos índices de condenações post mortem encontrados, com exceção de apenas 1 (um) município que teve três causas de condenações com índice superior aos demais, o que pode ser considerado um caso isolado.

Esse equilíbrio nos índices de condenações entre municípios demonstra que há uma uniformidade no sistema de integração estudado, ou seja, que as medidas tomadas pela empresa integradora no período pré-abate seguiram uma mesma linha de ação, independentemente da localização. 


\section{Conclusões}

De acordo com os resultados obtidos, pode-se concluir que: o conjunto de condenações post mortem de parciais em perus é maior do que o de totais, sendo a aerossaculite a principal causa de condenação. Também se observou que existe, na maioria das vezes, uma tendência positiva entre o au- mento da temperatura média ambiente na região oeste catarinense e o aumento dos índices de condenações post mortem em perus. E finalmente que, na região estudada, ocorre uma uniformidade na criação de perus, dada a semelhança entre os índices de condenações post mortem encontrados nos diversos municípios participantes do sistema de integração.

\section{Agradecimentos}

À CAPES, pelo apoio financeiro;

À equipe de médicos-veterinários e agentes de inspeção do SIF 104;

Ao Sindicato dos Produtores Rurais de Chapecó/SC, EPAGRI e Sadia S.A., pela cessão de importantes dados para elaboração deste artigo.

\section{Referências}

BRASIL. Portaria ㄲo 210, de 10 de novembro de 1998. Aprova o Regulamento Técnico da Inspeção Tecnológica e Higiênico-Sanitária de Carne de Aves. Diário Oficial[da] República Federativa do Brasil, Brasília, DF, p. 226, 26 de nov. 1998. Seção 1.

CASTRO, A. G. M. Anamnese, diagnóstico clínico e anatomopatológico. In: Júnior, A. B.; Macari, M. Doenças das Aves. Campinas: FACTA, 2000. 490 p. Pt. 2.6: Enfermidades do Sistema Respiratório. Cap. 2, p. 71-74.

DI FÁBIO, J. Doenças Avícolas relacionadas a E.coli. In:SEMINÁRIO AVES: NUTRIÇÃO, MANEJO, DOENÇAS, 5, 1992, Mangaratiba, RJ, p. 19-22.

FABRíCIO, J. R. Influência do estresse calórico no rendimento da criação de frangos de corte. In: Conferência Apinco de Ciência e
Tecnologia Avícolas, 1994, Campinas. Anais... Campinas, 1994. p. 129-136.

FERREIRA, A. J. P; KNÖBL, T. Enfermidades Bacterianas. In: Júnior, A. B.; Macari, M. Doenças das Aves. Campinas: FACTA, 2000. 490 p. Pt. 4.2: Colibacilose Aviária. Cap. 4, p. 197-208.

FIORETTO J.L. Cuidados com as aves no tempo quente. Revista Aves \& Ovos, São Paulo, v. 9, n. 1, p. 29-30, 1993.

HERENDA, D. C.; FRANCO, D. Poultry diseases and meat hygiene: a color atlas. lowa: lowa State University Press, 1996. 337 p.

JORDAN, F. T. W. et al. Poultry Diseases. 3. ed. Londres: Baillière Tindall, 1990. $497 \mathrm{p}$.

NETO, J. .P. Resíduos de antimicrobianos em alimentos. Revista do Conselho Federal de Medicina Veterinária, Brasília, DF, v. 7, n. 22, p. 65-71, mar./abr. 2001. 